\title{
Alignment between Curriculum, Textbook and Board of Intermediate and Secondary Education Question Papers of English at Secondary Level
}

\author{
Ameema Mahroof, Muhammad Saeed \\ University of the Punjab, Lahore, Pakistan \\ Email: ameema.mahroof@gmail.com
}

How to cite this paper: Mahroof, A. and Saeed, M. (2021) Alignment between Curriculum, Textbook and Board of Intermediate and Secondary Education Question Papers of English at Secondary Level. Open Access Library Journal, 8: e7282.

https://doi.org/10.4236/oalib.1107282

Received: April 2, 2021

Accepted: April 9, 2021

Published: April 12, 2021

Copyright $\odot 2021$ by author(s) and Open Access Library Inc.

This work is licensed under the Creative Commons Attribution International License (CC BY 4.0).

http://creativecommons.org/licenses/by/4.0/

(c) (i) Open Access

\begin{abstract}
This study deals with the alignment between National Curriculum, Textbooks, and Question papers of Board of Intermediate and Secondary Education (BISE) in the subject of English at secondary level. The purpose of the study was to check the alignment of National Curriculum for English Language, 2006 with the Textbooks of English for Grade IX-X, and to evaluate the Board of Intermediate and Secondary Education (BISE) question papers with reference to cognitive domain of Bloom's taxonomy and with the corresponding textbooks. This study was done through document analysis. The documents analyzed for the study were the National Curriculum for English Language, Textbooks of English for Grade IX-X, and question papers of BISE of year 2014 and 2015. The instruments used for this study were the 1) Curriculum Textbook Alignment Framework and 2) Curriculum Textbook Alignment Rubric. The question papers of Board of Intermediate and Secondary Education were analyzed through the checklist developed by researcher. It was validated through expert opinion. Findings of the study depict that the SLOs stated in the textbooks of English were not completely matched with the SLOs narrated in National Curriculum Furthermore, the textbooks are not very helpful in achieving those SLOs with the help of the assessment exercises given in the textbook because most of the questions given in the textbook are not related to SLOs of National Curriculum. Findings further report that the all the question papers of Board of Intermediate and Secondary Education (BISE) for year 2014 and 2015 focused on knowledge and understanding level of Bloom's taxonomy of cognitive domain and very less focus were given on application, analysis, synthesis and evaluation abilities. It was recommended that the same SLOs of National Curriculum of
\end{abstract}


English Language for Grade IX-X should be included in the textbooks otherwise the alignment will suffer and the SLOs of higher order thinking skills should also be included in the textbooks. There should be a balance between the higher level and lower level cognitive skills Paper setters should be well aware of the Bloom's taxonomy of cognitive domain and question papers should include items of all cognitive levels in accordance with assessment scheme of Board of Intermediate and Secondary Education, and specifications mentioned in the National Curriculum of English.

\section{Subject Areas}

Humanities \& Arts

\section{Keywords}

Textbooks, National Curriculum, Bloom's Taxonomy

\section{Introduction}

National goals are written in its objectives, policies \& curriculum documents. Curriculum document is considered to be the roadmap for the completion of national goals. For this reason, the books are developed in a way that the contents of it should be aligned with the curriculum document. If it's not aligned, then it will be difficult to accomplish the national goals. It is very important that the textbooks matched according to the curriculum document because it is used widely to guide learning. It is the backbone of instruction in educational fields. Textbooks help teachers in teaching and students in learning. It not only influences how and what students learn but how and what teachers should teach. (Mahmood, 2011) [1]. Textbooks are the base of guidelines in the education system of Pakistan. Tomlinson (2010) [2], further states that "textbooks prepare learners for examinations, help teachers by reducing their preparation time, help administrators to allocate lessons to teachers, standardize teaching, and provide teaching that would be useful to any learner anywhere at a specified language level".

Therefore, it is very impertinent to analyze the quality of textbooks according to the national curriculum. Furthermore, it is also important to check that exercises given in the textbooks according to Bloom's taxonomy and basic rules of item construction to investigate the shortcomings in it. Because it answers the following questions:

Does it satisfy the requirements of a nation? Whether the textbook promotes all levels of Bloom's taxonomy or not? Assessing course readings from these dimensions can recognize the benefits and negative marks of the course books.

Now the question is why the subject English? It is because English is being taught as a compulsory subject and medium of instruction all over the world is English. English is the language of internal communication, higher learning and 
better career options (Government of Pakistan, 2006) [3].

In Pakistan, Board of Intermediate and Secondary Education take the annual papers from grade 9 to 12 . These papers are made with regard to Blooms taxonomy of cognitive domain. Teachers and paper makers may sometimes face the challenge that either their developed papers are aligned with the curriculum and textbooks or not. Blooms taxonomy is developed by Blooms (1956) [4]. It has three domains; Cognitive, affective and psychomotor. Cognitive domain has six levels; Knowledge, Comprehension, Application, Analysis, Synthesis and Evaluation.

In Pakistan, the Federal Ministry of Education is in charge of keeping up the guidelines of training, in this way, the course readings are affirmed by Ministry of Education before these are permitted to use in the schools (Mahmood, 2011) [1]. Curriculum and textbook advancement and endorsement procedure is regulated by Curriculum Wing (CW), and it maintains curriculum standards from primary to higher secondary levels. Accordingly, four Provincial Textbook Boards (PTTB) one in every region is in charge of preparing, publishing, and marketing school textbooks (UNESCO, 1998) [5]. For the development of textbooks Provincial textbook board follows the guidelines given in national curriculum, after developing these textbooks they forward them to curriculum wing for review and approval. The CW constitutes a National Curriculum Review Committee (NCRC) for this purpose.

According to Karamouzian, Narcy-Combes \& Ahmad (nod) [6], textbooks approved by the Ministry or the authorities are not very much good in quality. They have lacking characteristics of a good book. Ministry of Education failed to set standards for format and design of textbooks plus there are not sufficient guidelines for developing the textbook.

Some empirical studies have been done on curriculum, textbook alignment and question papers in light of Bloom's taxonomy in different contexts. Different researchers have used diverse techniques for assessing the course book and for examining the inquiry paper with reference to Bloom's Taxonomy. For example, Saeed \& Rashid (2014) [7] conducted a research on the "Alignment between Chemistry curriculum and textbook". They recommended adequate training for the curriculum and textbook developers to ensure alignment between national curriculum and textbooks.

Mahmood (2011) [1] led an examination on course book assessment in Pakistan. His study talks about the attributes of a quality reading material and examines the presence and absence of these qualities in the course books endorsed by Ministry of Education, Pakistan in the light of established educational programs. He reasoned that the Curriculum Wing must give the criteria for course book assessment and survey in light of attributes of quality textbooks and it should be shared with the textbook writers.

Shah, Rafique, Shakir and Zahid (2014) [8] found that course readings are not assessed that is the reason we discover the mistakes in them. They concluded 
that curriculum is not able to fulfill its designed objectives due to the absence of evaluation system and the textbooks do not cope with the needs of the new generations.

\subsection{Objectives}

Objectives of the study were to:

1) Explore the alignment between English National Curriculum and Textbooks at secondary level.

2) Explore how far the English textbooks exercises developed according to various cognitive levels of blooms taxonomy at secondary level.

3) Analyze the questions papers of English with regard to blooms taxonomy of cognitive domain and basic rules of item construction.

4) Suggest measures to remove gaps between national curriculum and textbooks of English focusing assessment exercises and question papers of Board of Intermediate and Secondary Education.

\subsection{Research Questions}

Research questions of the present study are given below:

1) How far the Objectives, student learning outcomes and content of textbooks are matched with the National curriculum of English?

2) How far the textbooks exercises promote students' various cognitive abilities mentioned in the national curriculum with reference to Bloom's taxonomy?

3) How far secondary level question papers in the subject of English truly assess students' cognitive abilities with reference to Blooms taxonomy?

4) What measures will be taken to remove curriculum-textbooks gap and quality of question papers in context to Bloom's taxonomy?

\subsection{Methodology of the Study}

The study is qualitative in nature focusing on analyzing the curriculum, textbook and question papers of English.

This research was done through document analysis. Document analysis is a process for reviewing and evaluating a document. Like any other analysis method, this procedure is also required in dept study of the content for generating underlying meanings and to develop empirical knowledge (Corbin \& Strauss, 2008 [9]; see also Rapley, 2007 [10]).

The following documents were analyzed:

1) National curriculum for English language for Grade XI and X.

2) English Textbooks for Grade XI and X.

3) Question papers of Board of Intermediate and Secondary Education, Lahore in the subject of English for Grade IX and X of year 2014 and 2015.

The researcher intensively analyzed following documents to gain insight and producing rich explanations regarding their alignment with each other.

The researcher the past papers of English to find the root cause of problems in 
the development of papers. Analyzing past papers gives us the insight and knowledge to see the patterns of problems that might invisible in the present. For identifying the root cause of problems, it is important to first study the processes of papers development in the past.

For the study, there were total three tools were used:

1) Curriculum-Textbook Alignment Framework.

2) Curriculum-Textbook Alignment Rubric.

3) Self-made checklist.

Curriculum-Textbook alignment framework comprised of three sections; curriculum organization, Chapter analysis and Descriptive analysis.

Curriculum-Textbook alignment rubric analyzed the alignment within competencies, benchmarks, standards and SLOs of National Curriculum.

The third instrument was checklist developed by researcher to analyze the question papers according to Bloom's taxonomy and basic item construction rules.

\subsection{Data Collection and Analysis}

For the alignment of National Curriculum and textbook, three tables are developed. First, SLOs of textbook given in the start of unit are matched with their corresponding SLOs of National curriculum of English, 2006. A table was developed for this purpose; in the table the SLOs narrated in textbook are listed along with the SLOs given in the National Curriculum of English. Level of alignment which are fully aligned, partially aligned and not aligned was given in the table to check to what extent the SLOs are matched with each other.

In the second table, the alignment between textbook exercises and SLOs narrated in curriculum, related competencies, standards and benchmarks was investigated.

For this purpose, questions given at the end of unit were listed along with their related SLO's, benchmarks, standards and competencies given in the National Curriculum of English, 2006.

In the third table, questions given at the end of unit were checked with reference to Bloom's taxonomy of cognitive domain. Six levels of Bloom's taxonomy are mention in the table which is knowledge, understanding, application, analysis, synthesis and evaluation.

For the alignment between textbook and Board of Intermediate and Secondary Education papers, three tables were developed according to the questions given in the paper. Total eight questions were given in the Board of Intermediate and Secondary Education paper of English. One table was developed for the MCQS section of paper, this section covers the question number 1 of Board of Intermediate and Secondary Education paper.

Second table was developed for the short question answer, translation and summary or paraphrase. This table covers the question 2, 3 and 4 of paper.

Third table was developed for the different types of question given in the pa- 
per like direct/indirect speech, pair of words, essay or paragraph and translation of paragraph and it covers the question number five to eight.

In this table, these objective type questions were checked to know which question comes from which chapter of textbook and corresponds to which level of Bloom's taxonomy of cognitive domain.

\section{Findings}

The findings of the study have been divided into two major sections (a) alignment between National Curriculum and textbook for English Language Grade IX and X (b) and alignment between textbook and question papers of English for Grade IX and X of year 2014 and 2015. Alignment between National Curriculum for English Language Grade.

\subsection{IX and $X$ (2006) and Corresponding Textbooks.}

The SLOs stated in English textbooks of Grade IX and X were not the same copies of SLOs as listed in the National Curriculum for English language for Grade IX and X (2006). SLOs stated at the start of each unit were measured as (a) Matched (b) Partially Matched and (c) Not Matched, the exercise of each chapter was also aligned with the SLOs given at the National Curriculum and their evidence of alignment (book number) were also mentioned. So, unit and grade wise analysis of the two textbooks were conducted to achieve the objectives of the study and the findings are:

Grade IX and X:

1) Many SLOs stated at the start of each unit are not matched with the SLOs narrated in the National Curriculum of English Language Grade IX and X (2006).

2) The textbooks are not very helpful in achieving those SLOs with the help of the assessment exercises given in the textbooks because most of the questions given in the textbook are not related to SLOs of National Curriculum.

3) The questions at the exercise were only assessing the lower level ability of Bloom's taxonomy of cognitive domain, not a single question was designed to measure the student abilities of analysis, evaluation and synthesis.

4) Curriculum guidelines were not properly given in the curriculum document. It did not give details about the topic-wise weightage, cognitive domain categories weightage and time allocation to one topic etc.

$5)$ The sequence of topic in the book was from easy to difficult.

6) The competencies standards and benchmarks of the National Curriculum for English Language of Grade IX and X were aligned with the student learning outcomes. See table.

7) There were 5 competencies 8 standards 19 benchmarks and 110 SLOs in the National Curriculum of Grade $9^{\text {th }}$ and $10^{\text {th }}$ and only 81 SLOs. It means a major chunk of national curriculum was not included in the textbooks. It shows that textbooks are not thoroughly aligned with National Curriculum of English Lan- 
guage for Grade IX and X.

\subsection{Alignment between Textbooks for Grade IX and X and Board of Intermediate and Secondary Education Question Papers of Year 2014 and 2015}

Table 1 about paper analysis of Grade $9^{\text {th }}$ and $10^{\text {th }}$ of year 2014 and 2015 explains that in objective type all questions measuring the student abilities of knowledge, understanding and application and essay type questions measured student's comprehension and application ability. Only cognitive domain of Bloom's taxonomy is included in the papers and Cognitive domain categories like knowledge, comprehension and application are given preferences. Total 8 question papers were aligned with textbooks of English at secondary level. Question papers of year 2014 and 2015 for group I \& II were aligned with chapters of textbook of English for Grade IX and X. Total 9 questions were asked in question papers $(2014,2015)$ group I \& II for Grade IX and X 6 questions were aligned with textbook. 3 questions were not aligned with textbook because they relate to paper B.

\section{Conclusions}

It is clear from the findings that there is little alignment exists between textbooks and National Curriculum. The competencies, benchmarks were aligned with the SLOs. But the SLOs of the textbook are not the exact copies of the SLOs of the curriculum which decreases the alignment between curriculum and textbook. Assessment exercises given at the end of each unit were not assessing the SLOs narrated in National Curriculum and assessment exercises only assess students' knowledge ability and to some extend comprehension and application ability. Analysis, synthesis and evaluation abilities are neglected. It is obvious from findings of paper analysis of grade $9^{\text {th }}$ and $10^{\text {th }}$ that they only assessing student abilities about memorization and information. Higher level categories of cognitive domain are totally ignored. Findings of the study revealed that there is not proper coverage of the topics in the textbook because many SLOs are not addressed in the textbooks. It means that National textbook review committee was

Table 1. Categorization of questions according to the levels of blooms taxonomy.

\begin{tabular}{|c|c|c|c|c|c|c|c|c|}
\hline Year & Grade & Group & Knowledge & Understanding & Application & Analysis & Synthesis & Evaluation \\
\hline \multirow[t]{4}{*}{2014} & IX & Group I & 44 & 16 & 33 & - & - & - \\
\hline & & Group II & 41 & 19 & 40 & - & - & - \\
\hline & $\mathrm{X}$ & Group I & 59 & 14 & 27 & - & - & - \\
\hline & & Group II & 46 & 14 & 40 & - & - & - \\
\hline \multirow[t]{4}{*}{2015} & IX & Group I & 46 & 19 & 35 & - & - & - \\
\hline & & Group II & 28 & 18 & 57 & - & - & - \\
\hline & $\mathrm{X}$ & Group I & 46 & 14 & 40 & - & - & - \\
\hline & & Group II & 51 & 14 & 9 & - & - & - \\
\hline
\end{tabular}


not giving proper attention to the textbooks while approving or reviewing. Therefore, the ministry of education should focus on the quality of textbooks demanded by curriculum and also give proper guidelines to the textbook committee and textbook writers. There is also a lack age in curriculum, it does not provide content weightage and time allocation. It should also be included in the curriculum.

Higher level cognitive domain is neglected it seems that paper setter might not have proper information about Blooms taxonomy. It should be trained while making paper.

\section{Recommendations}

The following recommendations were made in the light of the study:

1) The SLOs of higher order thinking skills should also be included in the textbooks. There must be a balance between the upper order and lower order thinking skills of Bloom's taxonomy of cognitive domain in accordance with the National Curriculum and Board of Intermediate and Secondary Education Assessment Scheme.

2) The questions given at the end of each unit should be according to the SLOs of National Curriculum and should include all cognitive levels to promote students higher order skills.

3) The same SLOs of National Curriculum of English Language for Grade IX-X should be included in the textbooks otherwise the alignment will suffer and it will result in unsatisfactory learning achievement.

4) Board of Intermediate and Secondary Education paper setters should be careful while writing the paper and they should aware of the Bloom's taxonomy of cognitive domain and basic principles of test item construction.

5) Paper setters should include both lower and higher order thinking skills questions at the paper.

6) Teachers in the classroom should involve students in such activities which may enhance student's higher cognitive skills. In school exams, the papers should include questions that can assess various cognitive abilities mentioned in the national curriculum and Board of Intermediate and Secondary Education (BISE) Assessment Scheme.

\section{Conflicts of Interest}

The authors declare no conflicts of interest regarding the publication of this paper.

\section{References}

[1] Mahmood, K. (2011) Conformity to Quality Characteristics of Textbooks: The Illusion of Textbook Evaluation in Pakistan. Journal of Research and Reflections in Education, 5, 170-190.

[2] Tomlinson, B. (2010) Principles of Effective Materials Development. In: Harwood, N., Ed., English Language Teaching Materials. Theory and Practice. Cambridge 
University Press, Cambridge, 81-98.

[3] Government of Pakistan (2006) National Curriculum of English for Class IX-X, Islamabad. Ministry of Education, Curriculum Wing.

[4] Bloom, B.S. (1956) Taxonomy of Educational Objectives. Handbook I: The Cognitive Domain. David McKay Co Inc., New York.

[5] UNESCO (1998) UNESCO Statistical Yearbook. UNESCO, Paris.

[6] Karamouzian, F.M., Narcy-Combes, M. and Ahmed, F. (2014) A Post-Use Evaluation of Pakistani Secondary School English Textbooks. TESOL International Journal, 9, 15-37.

[7] Saeed, M. and Rashid, S. (2014) Alignment between Chemistry Curriculum and Textbooks at Secondary Level. The Sindh University Journal of Education, 43, 29-46.

[8] Shah, S.K., Rafique, S., Shakir, A. and Zahid, S. (2014) Textbook Evaluation of English for Academic Purposes by British Council. Research on Humanities and Social Sciences, 4, 104-114.

[9] Corbin, J. and Strauss, A. (2008) Basics of Qualitative Research: Techniques and Procedures for Developing Grounded Theory. 3rd Edition, Sage, Thousand Oaks. https://doi.org/10.4135/9781452230153

[10] Rapley, T. (2007) The Sage Qualitative Research Kit. Doing Conversation, Discourse and Document Analysis. Sage Publications Ltd., Thousand Oaks. 